\title{
TURNITIN? TURNITOFF: The Deskilling of Information Literacy
}

\author{
Professor Tara BRABAZON \\ Education and Head of School of Teacher Education \\ Charles Sturt University, AUSTRALIA
}

\section{ABSTRACT}

Plagiarism is a folk devil into which is poured many of the challenges, problems and difficulties confronting higher education. This article investigates how software -Turnitin in particular- is 'solving' a particular 'crisis' in universities. However, $I$ investigate how alternative strategies for the development of information literacy offer concrete, productive and imaginative trajectories for university staff and students.

Keywords: Plagiarism, intellectual integrity, information literacy, higher education.

\section{INTRODUCTION}

Most of us when explaining what digitization, computing, the internet, web and read write web have added to our lives respond with verby nouns:

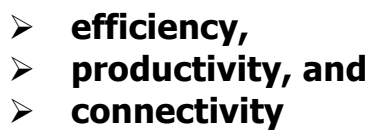

Some may describe the rapid delivery of information. A few may even recognize an expansion of knowledge. What is rarely mentioned and one of the causes of this efficiency is that an array of functions in our daily lives are now automated and displaced from patterns of conscious decision making. From spelling checkers to the defragmentation of discs, from predicting our search terms in Google through to remembering our interests when we visit Amazon, we move through life in a bubble of predictability.

The assumptions of efficiency and productivity block the realization of how we fill each day with tasks that did not exist twenty years ago. We also normalize, rather than medicate, bizarre online behaviour. Examples include those who insist on showing how clever they are by CCing an email to half of Yorkshire, managers who reply to serious issues on their blackberry or users of Twitter who think they are being clever and witty, rather than xenophobic trolls. How these learned, deskilled but increasingly automated behaviours link with learning is a key question. I have lived through the impact of digitization as a student, teacher and head of department. When I enrolled at the University of Western Australia in Perth in 1987, the library catalogue had just been digitized, and the word plagiarism was not used at any point during the degree. Yes, there were whispers about academics 'using' the work of their dissertation students.

Compare this situation to our present. I run inductions for new students, and have done so since 1997. Each year, plagiarism has crept further and further up the orientation agenda. Picture this scenario. Students work hard to gain entry into university. They are finally free to open a new chapter of their lives. I watch them arrive on their first day in higher education, anxious to meet new friends and are excited about the future. 
What do we do to them on their first day? Within one hour of their arrival -instead of speaking of hopes and dreams and congratulating them on their achievements and wishing them well- we push sanctions against plagiarism so aggressively they almost suffocate. As I sit in the auditorium, I see how we lose our students.

I see the shining joy leave their faces. A culture of blame, shame, judgment and ridicule is created. We never think that we as teachers are creating the problem that we most fear, by replacing teaching and learning with blaming and shaming. Instead of motivation and aspiration, we use academic dishonesty (Shariff and Ahamed 2014) and plagiarism.

This paper enters the troubling terrain of academic dishonesty. As more educational opportunities and professional development are undertaken digitally and at a distance from the physical buildings of a university, the software and hardware selected by academics becomes even more important to ensure both quality and quality assurance.

The focus of my article is Turnitin, the panopticon of plagiarism. This application certainly manages plagiarism. It catches and censors the cheaters. But are we missing something in this story? Indeed, are we missing the actual story? Each day, we make a choice between 'blaming' the internet for plagiarism and establishing a system of retribution to manage it, or recognizing that our current students are facing a range of complex social, economic and technological challenges that require more precise tools to address their concerns. The internet did not invent plagiarism. Plagiarism has many definitions (Briggs 2009), but it is increasingly being reified to copying and pasting digital text (Jocoy and DiBiase 2006).

This arbitrary and incorrect convergence of plagiarism and the internet has ignited educational managers' need to solve academic challenges by administrative means. A recent study of dissertations, comparing online and brick and mortar institutions, found that no significant difference between the originality indices of dissertations from traditional institutions and those from online institutions (Ison 2014, 272). The statistics of plagiarism need to be placed in context and -to deploy the Blum's phrase- "College Culture" (2009). McCabe, Butterfield and Trevino's two multicampus surveys found that $30 \%$ of students admitted to academic dishonesty in 1963, compared to $26 \%$ in 1993. The update of this study for 2002-2010 demonstrated a decline in 'padding' items into the bibliography and copying from another student's test, but remarkable similarities in many of the other modes and forms of academic misconduct (McCabe, Butterfield \& Trevino 2012). These results confirm that there is no internet-caused 'epidemic' as similar levels of plagiarism were reported in the analogue age. Instead, plagiarism requires a context and history.

Why in the last twenty five years has plagiarism moved from relative invisibility to the key scholarly crime in our schools and universities? Every era finds and invents the folk devils it requires for its time. The twentieth century folk devils moved from flaneurs to bankers, flappers to feminists, and from rock and roll to rap. It is clear and effective to construct a label, build a category and throw negativity, darkness, fear and loathing at an unspecified, ill-defined group that cannot fight back. Stuart Hall and others described this as Policing the Crisis. Youth is a great label to police a crisis. So is internet pornography. So is plagiarism (Decoo 2002). Part of the purpose of this article is to unpick this talk of 'crisis' and ask what are we are NOT talking about when we summon the folk devil of plagiarism. What is being hidden, what is being masked? Why are 'we' 'fighting' plagiarism? (Batane 2010) These are multiple and convoluted questions, but I offer an argument for the consideration of readers. 
With all the great benefits and gifts of digitization, the internet and the web, consider what we - students and citizens - have chosen to do with our online time. We are drawn to the easiest, the most trivial and the inane. We displace all the anger of our wasted opportunities and use of digitization. We displace the neglect of professional development of university academics over twenty years, so that all that is left is to discover plagiarism through software, rather than prevent it (MacDonald Ross 2004) with particular attention to information literacy, media literacy, discussions of academic integrity, curriculum development and multimodality.

In this paper, I argue that plagiarism is a proxy, a strategy to blame the victim, rather than consider what has happened to higher education in the last twenty years. We are now living with the consequences of quick and cheap fixes for teaching and learning for two decades. I unpick the 'management' of plagiarism in higher education, interspersed with testimony from my former students as I ask them about their experiences with plagiarism and Turnitin (Brabazon 2011a). But this is not only a paper of critique and diagnosis. I present ten strategies to turn off the automation of software and reboot our wetware, to reclaim our intelligence and capacity for consciousness, reflection and questioning of deskilling processes and practices. I disengage - just temporarily - the software, and reconnect information literacy with context for learning. ${ }^{i}$

\section{ASSIGN ASSESSMENT TO DEVELOP AN INFORMATION SCAFFOLD}

While software discovers plagiarism, the greater question is how it is prevented. It is easier to pay for an application and database, than spend the time and money to prevent plagiarism in the first place. The solution to plagiarism is not software, but information literacy. A key strategy that costs nothing except academic staff time and their professional development is the creation of an information scaffold in every subject, in every semester in a degree. As the phrase suggests, we need to find ways to position a scaffold -a ladder- into our assessment that is not buried in assumptions, or hidden behind end of semester exams or a stand-alone research project.

The key strategy I use to develop an information scaffold is assigning research proposals and annotated bibliographies as assessment (Ghezzi, Chumber and Brabazon 2014). Two decades ago, academics could assign stand-alone papers. Now, we need to teach -overtly and clearly- strategies for managing and organizing material for research. A research proposal of two hundred words in length teaches students the skill in writing abstracts, finding the originality in their research, while also being intellectually generous to the scholars who preceded them. It also allows teachers to discover problems early in a semester before a full paper is written. I assign a very specific annotated bibliography. Students must find twenty items, determined by modality, peer review and media. This strategy ensures that they are thinking actively about the nature of source material, particularly with regard to credibility.

Two scholarly monographs

Two refereed articles in an open access online journal

One blog

One scholarly lecture from YouTube

One vodcast

One offline magazine or newspaper article
Two print-based refereed articles

One PhD

One relevant social networking site

One podcast

One official website from a professional organization

One track or album of music 
One advertisement

One television programme
An item of material culture

One photograph from Flickr with

a Creative Commons License

One film

This is an interventionist, positive and proactive strategy. Doug Johnson revealed, Educators expend much effort trying to 'catch' plagiarism in student work. Teachers and library media specialists use various Web services and Internet search techniques to detect student work that is lifted from online sources. While such tools are necessary and can be effective, our time as educators would be better spent creating assignments that require original, thoughtful research and, therefore, minimize the likelihood of plagiarism in the first place (Johnson 2004).

This annotated bibliography is a diagnostic tool, but also profound for students because they learn to deploy media literacies when engaging with online sources. However, when I assigned this assignment to my fourth years in a Canadian university, the results were unusual. They could not manage it. They used Google for every search, but did not vary their keywords or vocabulary. They did not use the expertise of our librarian (Brabazon 2011b). They did not use Google Scholar. They did not use the Directory of Open Access Journals. For the supposed google generation, they had profound difficulty finding podcasts, vodcasts or websites from a professional organization. They could not find any podcasts. I added the word "podcast" into their search box and - as if by digital magic the podcasts appeared. Students had so many difficulties finding these sources that they almost gave up.

From: Sally

Subject: RE: And a happy Sunday to you all!

Date Sent: March 5, 2012 1:50 PM

To: Brabazon, Tara ()

Hey Tara,

I have a lot of anxiety about the sources for this paper, mainly because we have never had a breakdown of such particular sources and it is taking a long time. Do we lose a lot of marks if our sources are not all fitting into what you want?

Thanks,

Sally

$* * *$

These were fourth students within one month of graduation. The problem expressed through this email is not derived from a search engine. The problem is a lack of information literacy in an age of information obesity. Also Sally's comment about "it's taking a long time" is significant: it is easier to read blogs than an academic article. It is easier to watch a YouTube video of a bride falling over at a wedding than watching an important lecture recorded with a static camera.

The problems became worse. One week before the first assignment was due, I received another email.

From: Maggie

Sent: 14 March 2012 12:14 
To: Tara Brabazon

Subject: Re: Topic for Social Change

Hi TB,

I feel like you are going to hate me by the end of this.

I have a bunch of questions about some of the sources we need. Here they are:

$>$ How do you find a scholarly monograph? I get that you don't want a textbook, but how do I go about finding that?

$>$ For the ebook, it has to be strictly online? That's a hard find

$>$ What in the world is a refereed article? And of course how do you find those and know that they are refereed?

$>$ what is the difference between a vodcast and a youtube video (could be a stupid questions)

$>$ for the music item, could i use their theme jingle?

I think that might be it. . .

I feel horrible because I never leave things last minute and I just realized it was due on the 20th when $i$ thought it was due at the end of the month and now I'm scared!!! HELP

Within four weeks of graduation, a student needed help in finding a book and a refereed article. This is a horrifying but important story for our time. This is not only a 'digital problem.' They do not know what they do not know until prompted by challenging assessment of their information literacy. All information requires an understanding of its credibility, relevance, purpose, audience and appropriateness for its required context. Therefore attention is required on research training, database instruction and best use of search engines.

\section{HIGH QUALITY FEEDBACK}

I have a theory: there is an inverse relationship between the number of institutional surveys of student feedback and the quality of feedback that students receive. Online submission through learning management systems is increasingly enforced by university managers. The question is why? One justification is that the online submissions, rather than analogue based projects on an array of platforms and presentational modes, can be run through Turnitin. Preventing plagiarism is the guiding goal to our practice and process. Alternative models of feedback are displaced from discussion (Dochy, Segers and Sluijsmans 1999).

Plagiarism is easy to discover through automated software embedded into learning management systems. Such a process has little to do with teaching, and much to do with the administration of teaching. Benjamin Ginsberg, in The fall of the faculty: the rise of the all-administrative university and why it matters (2011), recognizes the cost of these 'cultures of planning,' through meetings, conferences, staff retreats, strategic planning and talking. The invention of targets and agendas ensures that "administrators engage in a number of make-work activities" (Ginsberg 2011, p. 41). Talking replaces doing through these cultures of planning. The focus and fixation on plagiarism rather than information literacy is part of what Ginsberg described as, "the ongoing transfer of power from professors to administrators" (2011, p. 167). There has been little discussion - and less professional development - of how the quality and mode of feedback has transformed through online submission. My students however were not so reticent.

My concern is not so much that my work is being scrutinised for plagiarism, but that originality percentages become the most important part of everything $I$ 
submit. Since Turnitin has been used regularly I seem to be receiving less and less feedback on my papers, leading me to believe that my professors are using Turnitin as a crutch, rather than spending much time reading what $I$ have written (Claire in Brabazon 2011a).

My fourth year students at a laptop university who had managed online submission for four years noticed very little feedback on their work and argued that increasingly the Turnitin report was actually a replacement for feedback.

This is not the fault of Turnitin. It is the fault of how it is used. A lack of professional development for academic staff is clear, misunderstanding the difference between compliance in detecting plagiarism and providing the most robust feedback that facilitates excellence and rapid scholarly development. Instead of deploying clear evaluative criteria, the learning management systems we deploy encourage basic rubrics. At its most reified, students receive a mark out of ten for grammar, a mark out of ten for referencing, and a mark out of ten for interpretation. By assessing these basic skills on a marking checklist, the 'standard' of a university student's scholarship is supposedly assured. This is a confusion of quality assurance with quality. Validation meetings are filled with discussions of summative and formative assessment, rather than asking more fundamental questions about the level of content being taught and evaluated. The focus is on form, rather than content. High quality feedback is crucial to the development of scholars and scholarship. James Cote and Anton Allahar realized the profound consequences of reducing scholarly commentary and interpretation and the increasing use of checklists.

When little is asked of students, and no feedback is given regarding how to become more proficient in areas where improvements could be made, many will simply drift through the educational system and into the workforce without knowing what they are - and are not-good at (Cote and Allahar 2011, 68).

The difficulty with the 'managerial turn' of higher education, is that university education is 'administered. ' Academics are experts, evaluating excellence rather than compliance, and recognizing flaws, inaccuracies and obscurity in ideas and interpretation. Turnitin and rubrics automate and de-skill assessment and expertise from university scholars. Students move through their degree without the deep and tough critiques that would improve their work.

\section{FIND STRATEGIES TO ENSURE THAT STUDENTS RECEIVE AND UNDERSTAND THE FEEDBACK}

The impact of online submission of assignments for a generation of students is having an impact. Let me share a secret story. I taught a large survey course, titled Introduction to Communication. First year is a transformative experience for the teachers and learners. I spend a lot of time marking, ensuring that the learning outcomes map over the assessment, and that the evaluative criteria are clear. Each paper takes about an hour to mark. Students learn rapidly and improve quickly when feedback is intense, customized and individualized. I had never doubted its value, until Christmas 2011. I marked 161 first year assignments through December for submission to the university on January 2, 2012. I then waited to return the assignments to students. 


\section{I waited.}

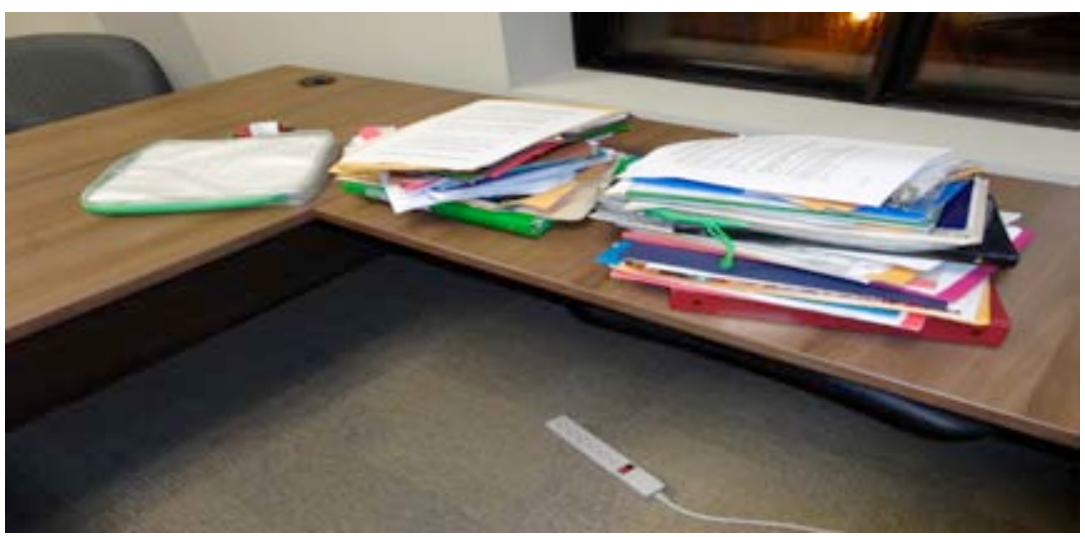

Figure 1. Marked Papers 1 (Photograph by Tara Brabazon)

\section{I waited.}

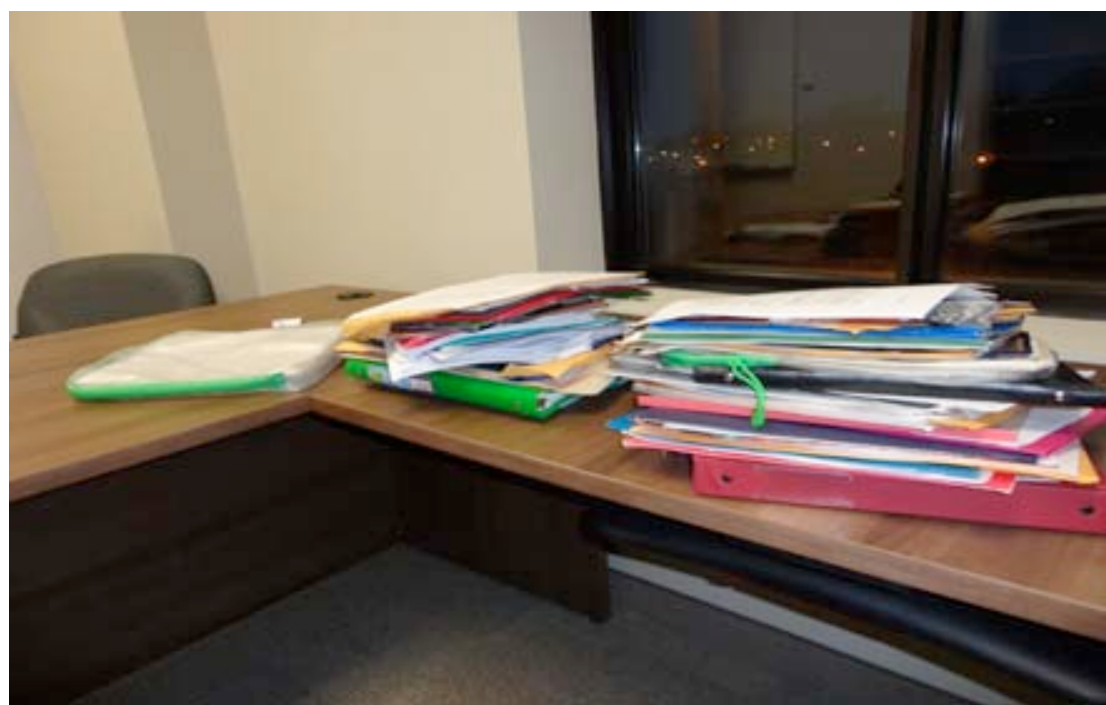

Figure 2. Marked Papers 2 (Photograph by Tara Brabazon)

\section{I waited.}

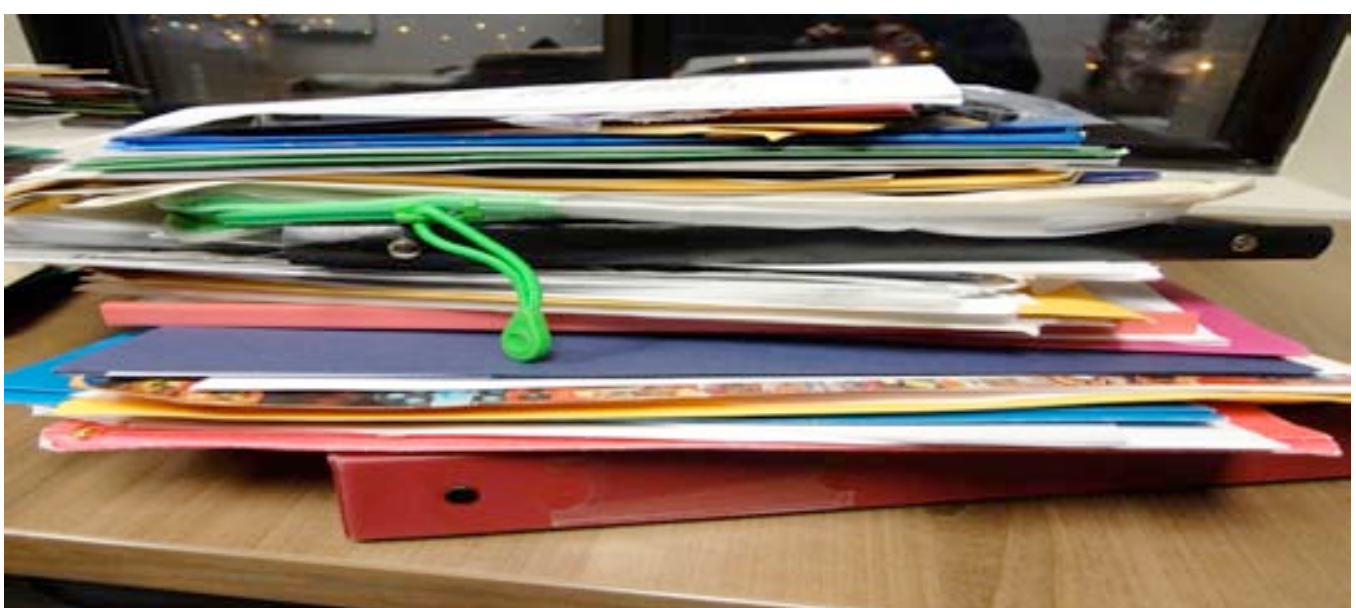

Figure 3. Marked Papers 3 (Photography by Tara Brabazon) 
For three months, I held the papers, all hand marked and with an A4 page of individualized commentary. Of the 161 papers, only four students picked up their work.

Every day in my office I stared at the pile of papers, waiting for students to receive their feedback to enable their improvement. Apart from the four students who picked up their papers, the rest were shredded in April.

For the first time in my teaching career of twenty years, I questioned the value of marking and assessment. This marking time was lost time. Part of this story it is about the managerialism that has marinated our educational system, where grade point averages are more important than learning. Part of it is about the flattening of expertise through the read-write web where all comments are of equal value. The students had received a mark for the paper online. Therefore they did not bother receiving their feedback.

That meant that they had no mechanism to improve, and they did not care. The value of assessment has been reduced to the mark. One my former students David, described this process:

I feel a bit offended when I'm told Turnitin is being used. The algorithms are completely inaccurate and don't take into account several different factors. It's like a machine is marking our work (David in Brabazon 2011a).

While our student surveys ask questions about feedback, when it is supplied, many (most) of the students do not retrieve it.

Students can now avoid receiving feedback. Turnitin is considered to provide "formative feedback" (Rolfe 2011). I often deploy the structure of an annotated bibliography and research proposal, followed by a full research paper. They receive feedback on the first part to improve the second. This strategy now fails because the students do not bother reading the feedback on the first stage. They do not improve, simply replicating the same errors. To re-energize a moment of reflection into the student's learning portfolio, I create a meta assignment on feedback, worth 10 percent of the semester's mark. Students must receive their detailed feedback from their first assignment and write a second assignment about what they did wrong, what went well and most importantly how they are going to use that feedback to improve their next assignment. They must demonstrate expertise in their own feedback to move through the information scaffold. When students picked up their feedback, such spoon feeding was not necessary. A metaassignment asks them to reflect on their feedback and how they will act on it.

Another effective solution that I have yet to attempt is built on the paradigm of the flipped classroom (King 1993). "Flipped Marking" is an attempt to reduce what Jaime Paris has described as students feeling "alienated from the university community," because of the focus on plagiarism rather than learning. He suggests involving peer marking throughout the process. The goal is clear.

To fight plagiarism I am arguing that students need to be told not to cheat and to be punished if they do, but I am also arguing that students need to be taught how to become invested members of an academic community. The plagiarism crises, $I$ am arguing, can be best addressed by using tools that encourage and privilege community building rather than by using tools that encourage academic isolation (Paris 2014).

Paris's argument is convincing and is worth an attempt. There may or may not be a plagiarism crisis. There is however a feedback crisis. The necessity for complex, 
challenging, rigorous and testing assignments that are evaluated with care and the commentary understood and acted upon is clear. Creating meta-assessment on assessment or a mode of flipped marking are both options to consider.

\section{DO NOT DISTRIBUTE POWERPOINT NOTES FROM LECTURES}

This maxim is so out of step with current practices, I almost hesitate to suggest it. However, a range of research projects have shown that no matter how much work and care and respect that academics put into learning management systems, the overwhelming function for which students use them is to download PowerPoint slides from lectures (Tobarra, Robles-Gómez, Hernández, Caminero 2014). There are two key problems with this downloading of slides. Firstly students do not learn how to take notes independently in a lecture and seminar. They have a crutch provided by their teacher which means they can maintain distractions in a lecture theatre, take text messages, scroll through Facebook's news feed, thinking that they will scrounge sufficient material from the academic's PowerPoint slide to pass.

herefore, they do not gain auditory literacies. There is an Empire of the senses (Howes 2005). The visual will dominate the sonic, the olfactory, the tactile and taste.

A particular dominant mode of information management will block the development of alternative literacies and multimodality. Students lose the capacity to take independent notes. Downloading slides is different from finding an independent pathway through material.

Further, there is a confusion between reading PowerPoint slides constructed by a lecturer and completing the required reading for scholarship. I bring students into my office to talk about their assignments, rather than simply return them. I asked them to show me their notes. They share notes from the lecture and seminar: there are no notes from the readings. One of the key causes of plagiarism is a lack of reading, being too reliant on a very few sources, often a textbook.

Even more frequently, the academic's PowerPoint slides are simply being downloaded and opened when assignments or examinations are pending. Downloaded PowerPoint slides provide a replacement for their own listening, thinking, selecting and writing. If they do not take notes, then they are never able to control the information environment. This problem can be solved - or at least started to be solved - by considering how they select information in the first place.

Instead of uploading my PowerPoint slides from lectures, I display a series of foundational files with names like "Lecture One Base Notes," "Lecture Two Base Notes" and "Lecture Three Base Notes. "

The key is in the title: students see a file that is linked with a lecture. They recognize something has been prepared. I provide six to eight slides in the base notes of the 80 or 90 I would use in a lecture and workshop.

This short package of slides is an orientation into the week's reading and teaching and is different from the material used in the lecture. 
Lecture Thirteen Time, space and identity: communication, literacy and social justice Sonic Session 13

Full lecture: Time, Space and Identity The big questions What is history? Who belongs? Who does not ... Authors: Tara Brabazon

C: $\mid$ Users $\backslash$ Tara $\backslash$ My Documents $\backslash$ Word $7 \backslash$ Introduction to Communication

Lecture base IC 12

Date modified: 27/11/2011 15:10

Checking in? When social networking becomes geosocial networking Sonic Session 12 Checking in:

when social networking becomes geosocial networking Deterritorialization: from home to homepage...

Authors: Tara Brabazon

C: $\mid$ Users $\backslash$ Tara\My Documents $\backslash$ Word $7 \backslash$ Introduction to Communication

迎四

Lecture Base IC 11

Date modified: 20/11/2011 10:03

Impairment, (dis)ability and communicating difference through analogue and digital space Sonic

Size: $42.8 \mathrm{MB}$

Session 11 Mobility is power: impairment, (dis)ability and communicating difference through analogu...

Authors: Tara Brabazon

C: $\backslash$ Users \Tara\My Documents\Word 7\Introduction to Communication

Lecture base IC 10

Cities, nations and reading the landscape Sonic Session 10 Lecture Ten - Marketing Place: cities, nations and reading the landscape National imaginings and reading the landscape City Imaging: What is it? Gl...

Date modified: 11/11/2011 14:50

Size: $14.8 \mathrm{MB}$

C: $\backslash$ Users $\backslash$ Tara $\backslash$ My Documents $\backslash$ Word $7 \backslash$ Introduction to Communication

Lecture base IC 9

Date modified: 06/11/2011 15:14

Lecture Nine Time for Timbits? Fast food, slow food, class and culinary communication Sonic Session 9 Size: 9.52 MB

Figure 4. Do not distribute full sets of PowerPoint slides

The content on these 'orientation' slides includes: title of session, a 3-6 minute podcast that orients the student into the week's teaching, the four key sections of the lecture, key questions, a structuring diagram of a key relationship, important theorists and a big question - 'Why this topic is important?'

\section{CASCADING ASSESSMENT}

Cascading assessment is a great strategy to ensure that students are working at the level required of them at university. I have the uncomfortable - but productive - privilege of being able to compare the international standards of higher education at very close quarters. The moment of rupture when I move between the systems is always startling. When I left Murdoch University in Western Australia, I was teaching first year students in a large survey course in Creative Industries. Six weeks later, I arrived at the University of Brighton to teach third year students in their first semester of their final year. Their academic standard was lower than the Australian first years. I then moved to Canada to teach at fourth year level and they had so little content knowledge of communication that their expertise was even lower than my English experience. In practice, this meant I added fifteen minutes to each lecture to define the most basic of terms, ideas and theories.

What had happened in the Canadian degree system? Two particular problems had emerged: no quality assurance and no benchmarking of skills, disciplinary knowledge and literacies. It was not clear to academics or administrators how the standards of first year were different from second year, third year and fourth year.

Without benchmarking, the students were taught the same material over and over again, and therefore they had the tendency to repeat the same content they used in earlier assessments. This is not only a form of self plagiarism, but the students are not allowing themselves to grow, develop, transcend and transform. Other problems that held back the level of student development included the removal or reduction of tutorials and seminars, little feedback, dated and basic textbooks assigned, and a reduction in contact teaching time. 
A lack of professional development for academics meant that few staff held teaching qualifications. This resulted in two problems: poorly constituted assessment, with a reliance on basic online quizzes, tests, midterms and exams, and secondly the study guides - which they referred to as syllabi - were all under eight pages in length. This was the work to be completed in a semester. The staff had created the plagiarism problem that they were trying to avoid by teaching so little content during the semester that the students were lacking theories and data on which to expand. The monitoring of plagiarism had become a proxy for regulating and verifying academic standards.

This is not simply my personal experience. A remarkable book on this topic is Richard Arum and Josipa Roksa's Academically Adrift: Limited Learning on College Campuses. They state that the quality of undergraduate learning is no longer a silent fear amongst academics, but a public problem for policy makers, politicians and employers.

They present a longitudinal study locating the barriers to learning in undergraduate degrees. The impact of students spending time on "non-academic activities" such as drinking and socializing results in a lack of preparation for academic study.
Many students come to college not only poorly prepared by prior schooling for highly demanding academic tasks that ideally lie in front of them, but - more troubling still - they enter college with attitudes, norms, values, and behaviors that are often at odds with academic commitment (Arum and Roksa 2011, p. 3).

They summon the customary argument that students are under prepared on entry into universities and conduct little personal study once on campus. But the authors then enact a knight's move. It is a productive one. They state, "If one is to cast aspersions on student cultures that exist on college campuses today, one would do well to focus equal attention on the faculty cultures and orientations" (2011, p. 5). Blame for a lack of educational achievement is not loaded onto students. Instead, a spotlight is shone on academics: their expectations, preparation and (in)ability to lift students to the required scholarly standards. They show that students learn very little through their four year degree. Arum and Roksa argued that academics must lift their methods, strategies and preparation, to create a context for intellectual excitement, motivation and rigour. Too often - because online learning has been sold to institutional managers as a cheap option, it is introduced to cut down contact hours with staff and reduce the depth and breadth of a university degree.

The way to intervene and interrupt this process, to create depth and breadth in learning, is to build cascading assessment. This is particularly useful if we are teaching in a university where the standards are low and the students do not know enough to be - in all conscience - awarded a degree. The cascades create an understanding of the student's level of learning, and multiple interventions in the process to both check and lift their achievement. To provide an example of assessment design that I created with Steve Redhead for a fourth year Interdisciplinary Legal Project, for students who in effect are asked to write a dissertation in their fourth year, but had never actually read enough beyond basic textbooks to be able to do it (Brabazon and Redhead 2012).

A four stage assessment was required:

1. Research Proposal

2. Key Theorist Paper

3. Research Diary

4. Final Research Project 
All the assignments were tethered so that there is continual feedback to check and correct errors and provide momentum for the next stage. Cascading is the correct verb. Each assessment dovetails into the next. Errors are picked up early in the semester and students who have not worked at the required standard through their degree improve rapidly. This is obviously very hard on staff. Marking must be done intensely, carefully and quickly so that it can feed into the next stage. But it means that students must structure their time and ideas and get organized. Through such a cascade, there is a rapidity of improvement, enhanced motivation and momentum, with each segment of assessment leading to a greater outcome.

\section{ORIENTATION MATTERS:}

Inspiration and Motivation, not Compliance

Much literature in education at the moment has the word 'crises in the title. Ginsberg describes the fall of the faculty (Ginsberg 2011, p. 11). Cote and Allahar describe the lowering of education (2011, p. 173). The question is how this talk of crisis creates a culture of compliance to medicate it.

Compliance culture is inappropriate for all forms of education, but particularly damaging for higher education.

As students are increasingly being branded as consumers and Key Performance Indicators are invented for staff, a culture of blame on teachers is created, rather than recognition of personal accountability and intellectual discipline. As Nicole Auer and Ellen Krupar confirm,

Universities have also fallen prey to the consumer mentality, this time directed at students. With the proliferation of 'Maymesters,' which contrive to give the illusion that you can condense a semester's worth of learning into a short few weeks, universities have given up some of the pretence that learning is the purpose of classes ... With students cut off by time constraints from interlibrary loan, retrieval or articles, or even the time to analyze information, what exact message are the students receiving on the value of any knowledge they may accidentally glean from their frantically paced class (Auer and Krupar 2001: 421).

The treatment of students as clients who consume education and are served by their teachers is transforming how these students/clients consider their assessment. Instead of being examined, they are being supported. Instead of being taught, they are facilitated. Nancy Girard confirmed that "students today pay a lot of money to attend college or university so many of them feel that any and all ways they find to excel are acceptable, including plagiarism" (Girard 2004, p. 14).

If universities are charging students for courses, course materials, maintenance fees, car parks and library cards, then it is a continuance of this ideology that money can also buy an essay. Consumers (students) are buying a service (education).

Through the use of language like graduate attributes, generic skills, flexibility and learning outcomes, the point of transformative and transgressive education is displaced. The base line of a successful assessment is not if the student has plagiarised. The question is where and how they learn to be outstanding scholars? The more that we drag higher education down to ticking boxes and frightening students, the more they will respond as consumers and complain about the service they have received. It is only when we render university education special - a privilege rather than a right, a gift rather than a service - that the inspirational components become part of the daily joy of education. 
If students are consumers of education, then the archetype of that statement is the explosion of the textbook market. When I was writing a textbook for an international publisher, I was given advice by the editor. It had a racial slur in it, which I will remove. But he told me "Tara, always remember that the audience for a textbook is a 19 year old girl who is much more interested in her boyfriend than learning anything. "This is offensive on many levels, about learners, about teachers, about scholarly writing and female students. There is a kernel of - not honesty - but warning in his words: do academics want to be a part of - and want to support - a publishing system that aims to facilitate mediocrity and laziness? Should the knowledge taught in North America and the United Kingdom be packed up - textbooked - and moved around the world without critique or question? Why do we think that by feeding our students bullet points, definitions in boxes and questions at the end of chapters that we are providing the foundation for scholarship? Aram and Roksa demanded standards of achievement, yet how can these standards be met with these low-grade textbooks? More significantly, students never gain the meta-skills to find further and relevant information.

From: Kathleen

Sent: Wednesday, 12 April 2006 10:43 AM

To: Tara Brabazon

Subject: assignment

Hey Tara

I know this is last- minute but unfortunately i'm a last minute girl. I need help with my assignment. I'm getting confused with the topic and I can't seem to find good references, or enough references for the topic.

When are your consulting hours? Because I desperately need help.

Love Kate

Turnitin discovers errors that have been recorded in their database. Such errors are easy to find if scholars around the world are assigning the same low-level textbooks year after year. But why I become irritated - on the student's behalf - is that they are spending a fortune on low grade textbooks, while the quality of open access journals has never been higher. To deploy open access journal articles in our subjects, more time is required from academic staff in finding current and interesting reading materials. By increasing the diversity of data used by students, they are not locked into paraphrasing a single textbook where the chances of plagiarism are much higher. Paraphrasing is located on the plagiarism continuum. The difference between paraphrasing and plagiarism is not clean, crisp and obvious (Shirley 2004). Every attempt at paraphrasing contains a risk within it (Atkinson 1957). There are productive programmes to develop "authorial identity," which describes a method to assist students in developing their own tone and mode of writing (Elander, Pittam, Lusher, Fox, Payne 2010). Turnitin is the determiner of whether the resultant prose is on the right side of paraphrasing or teeters into plagiarism.

\section{MAKE ASSIGNMENTS MORE COMPLEX}

Besides rendering reading materials more complex, it is important to ensure that assignments are tough and test knowledge in terms of form and content. The key in terms of plagiarism is not to assess via basic assignments that encourage paraphrasing, but find 
assignments that focus on interpretation, creativity, innovation and originality. Colin explored the much wider context of plagiarism.

The problem with Turnitin is a band-aid solution to a much wider problem of chronic underfunding of post-secondary institutions. It leads to lazy teaching and automatically assuming that students are plagiarizing (Colin in Brabazon 2011a).

It is very easy to blame students. But the teachers have a wide ranging responsibility in the current culture. I used to chair the academic misconduct meeting each semester and two courses would present between half and two thirds of the students in an annual academic misconduct meeting. These cases were not 'about' the students, but the assessment mode chosen by staff. One of these courses was a first year film unit. Students were asked to write the plot of the film. Is it any surprise that in re-writing a paragraph on the plot of classic cinema, the cases of plagiarism were high? The second course was a third year research methods course. Students were asked to write a paragraph on a textbook chapter about a research method. J. V. Bolkan diagnosed the problem in these courses.

Solid assessment and good teaching ... can't be over emphasized ... Motivation, of course, is the key. Motivated and engaged learners are much less likely to take shortcuts. If they're only in your classroom to get a grade and move on the potential for plagiarism will be greater (Bolkan 2006).

Innovative and rigorous assessment is both demanding and motivating. Yet asking university students to paraphrase and summarize is not appropriate. Are these the best assessment that could be developed in these areas? What about asking students to think about sound, film posters or bricolage? What if academics asked students to write a mock review for The Observer?

Similarly, for the research methods course, why not demonstrate that the students understand the method through application? When learning ethnography, ask students to go into a community in which they belong and write about insider and outsider relationships. When learning about unobtrusive research methods, send them to a graveyard. So many innovative assessment options are possible through the read-write web. Students can construct artefacts through the diverse functions of their mobile phone and learn to write in a succinct, careful and applied way through an exegesis on those images.

Some assignment modes are more likely to result in plagiarism than others. We should enhance and enable the creative-led options to assess learning outcomes in new ways that are available to us through digitization.

\section{RUN A STANDALONE INFORMATION LITERACY PROGRAMME IN THE FIRST SEMESTER OF A DEGREE PROGRAMME}

Culturally and historically, that which is fast dominates that which is slow. Therefore scrolling and skimming replaces reading. One way to establish the different modes of engagement with text is for librarians in the first semester of a university degree to provide a designated course or module on information literacy. Such a strategy establishes the faculty status of librarians, builds relationships between librarians and students at the start of the degree and ensures a minimum standard of information literacy. For example, the University of Wollongong library and librarians in Australia has StartSmart, a compulsory programme for all undergraduates and highly recommended for postgraduates (StartSmart 2014). Student results are withheld at the end of the first semester if the students do not complete this course. From the start of a student's degree, discussions of academic quality, standards and scholarship are the core and spine of a university education. 
Such a programme reveals our choice.

Academics can create a culture of plagiarism, grievance and compliance or information literacy, motivation and excellence.

There has never been more available information than in our present. However, the capacity to differentiate and evaluate it requires specialist care and attention. Without such a focus, we have to convince students that reading is required and scholarship is different from journalism.

From: Merv

Sent: Friday, 24 March 2006 5:11 PM

To: Tara Brabazon

Subject: RE: Creative Industries HELP!

Hi Tara

Sorry to be painful but this should be my last question. Do we really need to have ten references from the readers?

It's just that by coincidence (my parents bought me a subscription to Time) I have found a couple of articles, one regarding obesity in America and one about everyday people creating wealth through the internet (with blogs, short films etc).

I'd like to use these but I feel that I am getting too wound up on having ten references from the unit material,

Have a good weekend

Merv

$* * *$

The problem is - within the managerial university - the detection becomes the outcome, the 'success.' Actually plagiarism is a symptom, a diagnosis for a lack of information literacy. Nicole Auer and Ellen Krupar realized that,

Librarians are in a unique position to help prevent and detect plagiarism by forming partnerships with faculty to re-examine assignments and instructional sessions and by informing them of Internet paper mills and useful Internet search strategies (Auer and Krupar 2001, 415).

This balanced and considered response was written in 2001. Consider the movement of funding away from libraries and librarians and towards software and hardware in the subsequent decade. Disintermediation of information systems has resulted in software 'discovering' plagiarism, rather than validating librarians and information literacy programmes that can prevent it (Auer and Krupar 2001).

\section{PROFESSIONAL DEVELOPMENT OF ACADEMIC STAFF}

Many of the 'causes' or - to be more precise - the casual relationships that have created a culture of plagiarism are avoidable:

$>$ do not use textbooks,

$>$ generate demanding assessment and

$>$ change that assessment each year. 
There are so many positive options: use and trust the expertise of librarians, create information scaffolds and cascading assessment, and construct meta-assessment for students so they must log the feedback. Most of the initiatives I have discussed in this article are not demeaning, ridiculing or attacking students. The focus is on the behaviour, not the student (Powell 2012). Instead, this paper is questioning the 'business as usual' behaviour of staff. It is easy to blame students. It is particularly easy at the moment when we are receiving emails where they demonstrate - overtly and clearly - laziness, mediocrity and boredom. But what about teachers? Who gains from a discourse where plagiarism is definitive, trackable and clear? Instead, Shelley Angelil-Carter confirmed three modes of plagiarism:

$>$ cheating (deliberate fraud),

$>$ non-attribution (through ignorance of referencing models)

$>$ and paraphrasing that is simply too close to the original source (AngelilCarter 2000).

Edward Winter added the rather complex terrain of 'self-plagiarism.'

This occurs when an author uses his or her work that has been published previously elsewhere. Among other aspects, infringement of copyright enters the frame. Before a high-horse is mounted, consider the challenges faced when describing methods. If a particular technique is used repeatedly in one's work, it soon becomes taxing to describe that technique in a different form of words. Attempts to get round the problem by using the expression, 'The technique has been described in full elsewhere so only a brief outline is presented here' means that a reader has to go to another source with the attendant inconvenience that this brings. Often, reviewers challenge this approach (2006, p. 113).

Clearly, the determination of (self) plagiarism and citation is not as precise as the software-evangelist administrators may wish. It is convenient to define it as "recycling of assignments" (Halupa 2014, p. 121). In reality, such definitions are dependent on the parameters of different institutions (Halupa 2014). Similarly, there is the messy and complicated issue of senior academics 'claiming' or being named as an author for other's intellectual work. If students have seen senior scholars who have little contribution in an article adding their name to research, what lessons are being learnt about intellectual integrity?

Plagiarism is multi-phase and multi-causal. We need to demand more of our students, but really we need to demand more of our university academics. While academics may hold a doctorate - confirming expertise in content - holding a teaching qualification confirms expertise in form. Staff need both.

Without either of these elements, the staff members do not have the expertise to manage the high level of both form and content required at university level. When academics lack intellectual ability, it is completely understandable that staff cut corners, use easy textbooks, rather than having to work harder to master new, innovative and challenging content through open access journal articles and assign basic - rather than creative assessment items. I can always diagnose a teacher not managing form and content. They fill tutorials and lectures with student presentations, using the excuse of student-centred learning.

The truth is that the staff member either cannot be bothered or does not know how to create innovative learning. I will give you an example of this. In Canada, I taught at a laptop university, but the laptop became an excuse to reduce student contact. I remember an awful moment when I emailed an administrator to thank him for the timetabling information for the three hour lecture. I asked him where and when the 
seminars were being held for the $\mathbf{1 6 0}$ first year students. He replied that there were no tutorials or seminars.

The students had a lecture. They had a laptop. That is enough. These three hour lectures in a barn of a room, where every student plugged in their laptop, were the toughest teaching I have ever done.

Ironically, I received the highest teaching reviews of my career, but the time involved in creating useful learning experiences for 160 students in a lecture theatre completely unsuitable to any form of innovative teaching was immense.

I always arrived well before each of my sessions, as it is a good time for students to sit and have a relaxing chat with me when they were attending the campus anyway.

A by-product of this process was that I saw the academic in the session before mine. For the first two weeks, he delivered a lecture in a three hour slot. He filled an hour and then released them.

Then for the rest of the semester - the following eleven weeks - he filled the lecture time and space with student PowerPoint presentations. ach week I thought this must be the last session, as these sweaty students darkened the room and proceeded to read from their slides. Instead, these presentations filled the entire semester's teaching.

Each week 'the audience' (students) became smaller until by the end, the last presentations in week twelve, there were fewer students in the audience than in the group delivering the content.

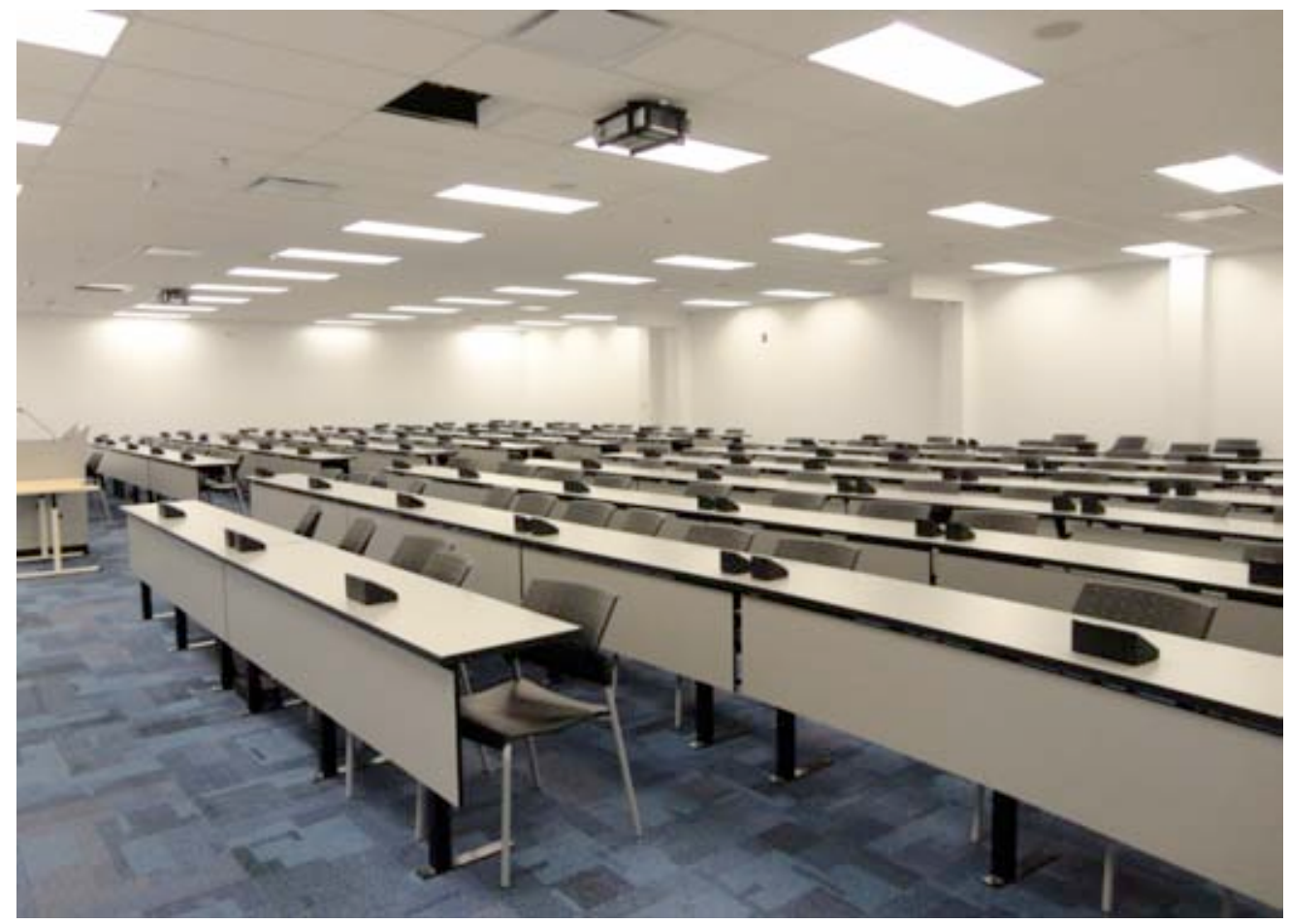

Figure 5. Learning architecture (Photograph by Tara Brabazon)

These students may not have plagiarized content, but the bigger question is, how much had they actually learned? 


\title{
CONCLUSIONS
}

J. V. Bolkan, as early as 2006 , explained that plagiarism is a proxy and a mask for a deeper discussion about the nature of teaching and learning.

\begin{abstract}
Many educators blame the internet for what they perceive as the rise of plagiarism. Although the Internet certainly enables more efficient plagiarism, blaming it for widespread copying is akin to blaming a bank robbery on the presence of cash in the building. It is a factor, of course, but not the root cause of the behavior. Just as with bank robbery, the solutions to plagiarism must be multifaceted. Efforts must be directed at prevention as well as detection and punishment. Banks don't leave piles of cash stacked by the front door. Educators should take care to make assignments that hinder plagiarists. It is also important to remember that it isn't just vaults and security guards stopping bank robberies. The vast majority of people wouldn't rob a bank even if they could (Bolkan 2006, p. 4).
\end{abstract}

Turnitin is a gastric band for plagiarism. It may block it, but it does not address the key problem: a lack of information literacy.

Only when enabling professional development, enhancing assessment and increasing the role of librarians may we move our students from information to knowledge.

Author Note: An earlier version of this paper was delivered as the keynote address at the Plagiarism.org 2012 conference at Gateshead, UK. This session was recorded and uploaded to YouTube.

\section{BIODATA and CONTACT ADDRESSES of the AUTHOR}

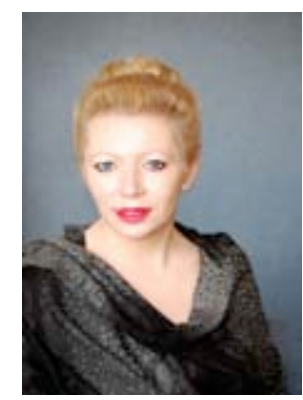

Tara BRABAZON is the Professor of Education and Head of the School of Teacher Education at Charles Sturt University (Australia), Fellow of the Royal Society for the encouragement of Arts, Manufactures \& Commerce (RSA) and Director of the Popular Culture Collective. Tara has worked in eight universities in four countries. She has won six teaching awards, including the National Teaching Award for the Humanities, and has published 16 books and over 170 refereed articles and book chapters. Her new books are titled Digital Dieting: From Information Obesity to Intellectual Fitness (Ashgate, 2013), City Imaging: Regeneration, Renewal, Decline (Springer, 2013), Digital Wine (Springer, 2014), Enabling University (Springer, 2014) and Unique Urbanity (Springer, 2014).

\section{Professor Tara BRABAZON}

Professor of Education and Head of School of Teacher Education

Charles Sturt University, AUSTRALIA

URL: http://www. brabazon. net

Email: tbrabazon@csu.edu.au

\section{REFERENCES}

Angelil-Carter, S. (2000): Stolen Language. London: Pearson ESL.

Arum, Richard and Roksa, Josipa (2011): Academically adrift: limited learning on college campuses. Chicago: University of Chicago Press. 
Atkinson, J. W. (1957): Motivational determinants of risk-taking behaviour. Psychological Review, Vol. 64, pp. 359-372

Auer, Nicole \& Krupar, Ellen (2001): Mouse Click Plagiarism. Library Trends. Winter. https://www.ideals. illinois. edu/bitstream/handle/2142/8353/librarytrendsv49i3d_opt. pdf

Batane, Tshepo (2010): Turning to Turnitin to Fight Plagiarism among University Students. Educational Technology \& Society. Vol. 13, No. 2, pp. 2-12.

Blum, Susan (2009): My Word!: Plagiarism and College Culture. New York: Cornell University Press.

Bolkan, J. V. (2006): "Avoid the plague: tips and tricks for preventing and detecting plagiarism," Journal of Vocational Education and Training, Vol. 33, p. 4-14.

Brabazon, Tara (2011a): Turnitin Turnitoff. Libsyn. October 27.

http://traffic.libsyn.com/tarabrabazon/Turnitin_Turnitoff.mp3.

Brabazon, Tara (2011b): Tara talks with librarian Stephanie Orfano. Libsyn. , December 11. http://traffic.libsyn.com/tarabrabazon/Tara_talks_with_librarian_Stephanie_Orfano. mp3.

Brabazon, Tara (2013): Turnitin? Turnitoff. YouTube, https://www.youtube.com/watch?v=eymt3V7J5zc\&feature=youtu. be.

Brabazon, Tara and Redhead, Steve (2012): Cascading assessment in legal education. Libsyn, June 6.

http://traffic.libsyn.com/tarabrabazon/Cascading_assessment_in_legal_education.mp3

Briggs, Robert (2009): Shameless! Reconceiving the problem of student plagiarism. Angelaki. Vol. 14, No. 1, pp. 65-75.

Cote, James \& Allahar, Anton (2011): Lowering higher education: the rise of corporate universities and the fall of liberal education. Toronto: University of Toronto Press.

Decoo, Wilfried (2002): Crisis on campus: confronting academic misconduct. Cambridge: MIT Press.

Dochy, F. Segers, M. and Sluijsmans, D. (1999): The use of self-,peer and co-assessment in higher education: a review. Studies in Higher Education. Vol. 24. No. 3. pp. 331-350.

Elander, James, Pittam, Gail, Lusher, Joanne, Fox, Pauline, Payne, Nicola (2010): Evaluation of an intervention to help students avoid unintentional plagiarism by improving their authorial identity. Assessment and Evaluation in Higher Education. Vol. 35, No. 2, pp. 157-171.

Ghezzi, Pietro, Chumber, Sundeep and Brabazon, Tara (2014): Educating Medical Students to Evaluate the Quality of Health Information on the Web. In Luciano Floridi and Phyllis Illari (eds. ): The Philosophy of Information Quality. Berlin: Springer, pp. 183-199.

Ginsberg, Benjamin (2011): The fall of the faculty: the rise of the all-administrative university and why it matters. Oxford: Oxford University Press.

Girard, Nancy (2004): Plagiarism: an ethical problem in the writing world. AORN Journal. No. 80, pp. 13-15. 
Halupa, Colleen (2014): Exploring student self-plagiarism. International Journal of Higher Education. Vol. 3, No. 1, pp. 121-126.

Howes, David (2005): Empire of the Senses, London: Bloomsbury.

Ison, David (2014): Does the online environment promote plagiarism? A comparative study of dissertations from brick-and-mortar versus online institutions. MERLOT Journal of Online Learning and Teaching.

Vol. 10, No. 2, pp. 272-282

Jocoy, Christine \& DiBiase, David (2006): Plagiarism by adult learners online: a case study in detection and remediation. International Review of Research in Open and Distance Learning. Vol. 7, No. 1, pp. 1-15.

Johnson, Doug (2004): Plagiarism-Proofing Assignments. Phi Delta Kappan. Vol. 85, pp. 549-553.

King, Alison (1993): From sage on the stage to guide on the side. College Teaching. Vol. 41, No. 1, 1993, pp. 30-45.

McCabe, Donald, Butterfield, Kenneth \& Trevino, Linda (2012): Cheating in college: why students do it and what educators can do about it. Baltimore: John Hopkins University Press.

MacDonald Ross, George (2004): Plagiarism in philosophy: prevention better than cure. Discourse: learning and teaching in philosophical and religious studies. Vol. 3, No. 2, pp. 23-57.

Paris, Jaime (2014): Flipped marking and plagiarism avoidance in a digital age. Digital Studies. http://www.digitalstudies.org/ojs/index.php/digital_studies/article/view/272/324

Powell, L. (2012) "Understanding plagiarism: developing a model of plagiarising behaviour," $5^{\text {th }}$ International Plagiarism Conference. Newcastle, $16^{\text {th }}-18^{\text {th }}$ July.

Rolfe, Vivien (2011): Can Turnitin be used to provide instant formative feedback? British Journal of Educational Technology. Vol. 42, No. 4, pp. 701-710.

Shariff, Habib \& Ahamed, Riyaz (2014): Academic dishonesty on the internet and suggested strategies to be used by academic staff to minimize the trend. International Journal of Information Systems and Engineering. Vol. 2, No. 1, pp. 32-40.

Shirley, Sue (2004): The art of paraphrase. Teaching English in the Two Year College. Vol. 32, No. 2, 2004, pp. 186-188.

StartSmart (2014): University of Wollongong, https://www. uow.edu.au/student/services/fye/resources/startsmart/index. html

Tobarra, Llanos, Robles-Gómez, Antonio, Ros, Salvador. Hernández, Roberto, Caminero, Agustin, (2014): Analyzing the students' behavior and relevant topics in virtual learning communities. Computers in Human Behavior. Vol. 31, 2014, pp. 659-669.

Winter, Edward (2006): Editorial: Plagiarism. Journal of Sports Science. Vol. 24. pp. 113. 